\title{
Rituals Enhance Consumption
}

\section{Citation}

Vohs, J., Y. Wang, F. Gino, and M. I. Norton. "Rituals Enhance Consumption." Psychological Science (forthcoming).

\section{Permanent link}

http://nrs.harvard.edu/urn-3:HUL.InstRepos:10686852

\section{Terms of Use}

This article was downloaded from Harvard University's DASH repository, and is made available under the terms and conditions applicable to Open Access Policy Articles, as set forth at http:// nrs.harvard.edu/urn-3:HUL.InstRepos:dash.current.terms-of-use\#OAP

\section{Share Your Story}

The Harvard community has made this article openly available.

Please share how this access benefits you. Submit a story.

Accessibility 


\title{
Running Head: RITUALS ENHANCE CONSUMPTION
}

\section{Rituals Enhance Consumption}

\author{
Kathleen D. Vohs ${ }^{1}$ \\ Yajin Wang $^{1}$ \\ Francesca Gino ${ }^{2}$ \\ Michael I. Norton ${ }^{2}$ \\ ${ }^{1}$ Carlson School of Management, University of Minnesota \\ ${ }^{2}$ Harvard Business School, Harvard University
}

Author Note: Kathleen D. Vohs and Yajin Wang, Carlson School of Management, University of

Minnesota; Francesca Gino and Michael I. Norton, Harvard Business School, Harvard

University.

Correspondence: K Vohs, kvohs@umn.edu.

Word count: 3913 


\begin{abstract}
Four experiments tested the novel hypothesis that ritualistic behavior potentiates and enhances the enjoyment of ensuing consumption - an effect found for chocolates, lemonade, and even carrots. Experiment 1 showed that ritual behaviors, compared to a no-ritual condition, made chocolate more flavorful, valuable, and deserving of behavioral savoring. Experiment 2 demonstrated that random gestures do not boost consumption like ritualistic gestures do. It further showed that a delay between a ritual and the opportunity to consume heightens enjoyment, which attests to the idea that ritual behavior stimulates goal-directed action (to consume). Experiment 3 found that performing rituals oneself enhanced consumption more than merely watching someone else perform the same ritual, suggesting that personal involvement is crucial for the benefits of rituals to emerge. Last, Experiment 4 provided direct evidence of the underlying process: Rituals enhance consumption enjoyment due to the greater involvement they prompt in the experience.
\end{abstract}

Keywords: Rituals; Consumption; Enjoyment; Involvement; Decision Making 
Rituals mark many life events, big and small. From sports performance to taking exams, people use systematized sequences of behaviors to prepare for and mark events. Rituals play a particularly prominent role in both ancient and modern consumption occasions; food historians have catalogued the countless rituals that surround the slaughter, preparation, and consumption of food and beverages (Tannahill, 1995). On an everyday level, Rossano (2012) depicted the birthday ritual as taking the typical act of eating and ceremonializing it with ritualized actions placing the entire cake with candles ablaze in front of the special person, singing (often off-key), and prompting a wish to be made. While the prevalence of rituals in consumption settings is well-known, to our knowledge there have been no empirical tests of rituals' effect. In fact, rituals have been studied almost exclusively with qualitative designs, making it "impossible" (Rossano, 2012, p. 542) to draw causal inferences about rituals' power to change thoughts, feelings, and behavior.

The current experiments systematically had some people perform rituals but not others, and then assessed consumption experiences (eating, drinking) for all. Given their long joint history, we predicted that the experience of consuming would be enhanced - meaning enjoyed more, including tasting more flavorful, being savored and valued — when preceded by rituals than otherwise.

\section{How Rituals Might Aid Consumption}

Our prediction that rituals have a causal impact on the experience of consuming has hints in anthropology. Visser (1992) described meal rituals as arousing desire. The French offer a notable case study: known for their love of food, they — not coincidentally — heavily ritualize eating, likely a major reason why "French kids eat everything" (Le Billion, 2012). 
The question of why rituals would benefit consumption arises. Rituals are known to increase involvement in subsequent acts (van der Hart, 1983), with involvement defined as deriving pleasure from the act beyond its practical utility (Trevino \& Webster, 1992). Accordingly, we reasoned that heightened involvement may brighten consumption's pleasurable aspects. We therefore tested involvement as a driving force behind rituals' effects on consumption, and did so by via measurement and manipulation (Spencer, Zanna, \& Fong, 2005). We defined rituals as symbolic activity that often includes repeated and unusual behaviors occurring in fixed, episodic sequences (Crew \& Boutcher, 1986; Cohn, 1990; Rook, 1985; Schippers \& Van Lange, 2006). Operationally, we opted to use multiple and novel ritual forms to show that a broad range of behaviors - if performed in a systematic, contextualized, stereotypy fashion - can enhance consumption. To test the power of rituals to enhance consumption, we used between-subjects designs and randomly assigned participants to condition.

\section{Experiment 1: Do Rituals Enhance Consumption?}

Experiment 1 tested the basic question of whether rituals enhance consumption. Participants tasted chocolate, before which they did or did not perform a ritual. We measured four outcomes: behavioral savoring, willingness-to-pay, flavor, and overall enjoyment. We predicted that participants who performed a ritual would find the taste more flavorful, as well as savor, value, and enjoy the chocolate more than those who did not perform a ritual.

\section{Method}

Participants. Fifty-two students ( 32 female; $M_{\text {age }}=22.10, S D=2.88$ ) participated in exchange for $\$ 15$. Participants were randomly assigned to one of two conditions: ritual versus no ritual. 
Procedure. As part of a consumer study, participants in the ritual condition were instructed, "Without unwrapping the chocolate bar, break it in half. Unwrap half of the bar and eat it. Then, unwrap the other half and eat it." In the no-ritual condition, participants relaxed for approximately the same duration and then ate the chocolate.

We measured behavioral savoring by recording how long participants spent eating the chocolate (Quoidbach et al., 2010). Onscreen instructions told participants to press a button when they started tasting the chocolate and another button when they completed the tasting. Savoring was measured as duration between button presses.

Next, participants answered subjective measures of enjoyment with three items: "I really enjoyed tasting the chocolate," "I savored every bite," "I really enjoyed the consumption experience of tasting the chocolate" ( $1=$ strongly disagree, $7=$ strongly agree $)$. The average of the items formed an enjoyment index $(\alpha=.88)$. As a measure of value, participants indicated their willingness to pay for the chocolate.

Last, participants rated the chocolate's taste: "How rich/sweet/sugary does the chocolate seem to you?" using 7-point scales ( $1=$ not at all; 7=very much). The average of these items formed a measure of flavor $(\alpha=.59)$.

\section{Results and Discussion}

Consistent with predictions, participants in the ritual condition reported enjoying the consumption experience more than those in the no-ritual condition $(\mathrm{M}=5.95, \mathrm{SD}=0.98$ vs. $\mathrm{M}=5.15, \mathrm{SD}=1.20), \mathrm{t}(50)=2.65, \mathrm{p}=.01, \mathrm{~d}=0.73$. Mirroring the ratings of overall enjoyment, participants in the ritual condition spent more time consuming the chocolate $(\mathrm{M}=29.03 \mathrm{sec}$., $\mathrm{SD}=17.83$ vs. $\mathrm{M}=19.93, \mathrm{SD}=16.30), \mathrm{t}(50)=1.74, \mathrm{p}=.06, \mathrm{~d}=0.53$. In addition, participants in the ritual condition were more willing - literally - to put their money where their mouth was: they 
reported being willing to pay more for the chocolate $(\mathrm{M}=\$ 0.59, \mathrm{SD}=0.32)$ than did participants in the no-ritual condition $(\mathrm{M}=\$ 0.34, \mathrm{SD}=0.29), \mathrm{t}(50)=2.93, \mathrm{p}<.01, \mathrm{~d}=0.82$. Finally, participants who performed the ritual also reported that the chocolate was more flavorful $(\mathrm{M}=5.58, \mathrm{SD}=0.65)$ than did those in the no-ritual condition $(\mathrm{M}=5.22, \mathrm{SD}=0.66), \mathrm{t}(50)=2.16, \mathrm{p}=.053, \mathrm{~d}=0.55$.

Discussion. Experiment 1 supported the hypothesis that rituals can enhance consumption. We demonstrated the impact of a ritual, compared to a non-ritual condition, on self-reports of enjoyment, actual behavioral savoring, and higher valuation of the experience as indicated by participants' willingness to pay more for the chocolate bar.

\section{Experiment 2: Rituals versus Random Gestures, and the Power of Delay}

Experiment 2 had four goals. First, we have not yet tested a design in which participants in the no-ritual condition performed any movements, which raises alternate explanations for Experiment 1's results. Therefore, Experiment 2 instructed non-ritual condition participants to perform movements. Based on anthropological literature linking rituals to heightened pleasure when consuming (Le Billion, 2012; Visser, 1992), we predicted that ritualized behaviors would improve consumption beyond the effect of random gestures.

Second, we tested whether anticipated enjoyment would be higher in the presence of rituals. Anticipated enjoyment is a critical component of utility and provides a separate source of pleasure from actual consumption (Loewenstein, 1987). We predicted that rituals, compared to random gestures, would have a positive effect on both anticipated and actual consumption.

Third, our theory is that rituals heighten involvement in the consumption act. If true, then a break between the ritual and consumption ought to stimulate the drive to consume, which we predicted would further heighten rituals' effects on enjoyment. We derived this prediction from research showing that a delay between goal cues and the opportunity to enact goal-directed 
behavior potentiates the ensuing behavior (Förster, Liberman, \& Friedman, 2007). We therefore expected that participants who performed a ritual and then must wait before consuming would show the highest enjoyment.

Last, we altered what participants consumed from the sublime (chocolate) to the mundane: carrots. We used healthy food as a strong test of our hypothesis that rituals can enhance enjoyment of a neutral (viz. not strongly hedonic) stimulus. ${ }^{1}$

\section{Method}

Participants and design. One hundred-and-five students (59 female, $\mathrm{M}_{\mathrm{age}}=22.14$, $\mathrm{SD}=2.74$ ) from the United States participated in exchange for extra course credit. They were randomly assigned to a 2 (ritual/random) by 2 (delay/no delay) design.

Procedure. As a session on several ostensibly unrelated studies, participants learned that the first involved vegetables. Three plastic bags of carrots were arranged on the table.

Participants in the ritual condition performed an identical set of gestures and movements before they tasted each of three carrots, one from each bag. Participants in the random condition, in contrast, performed different gestures before consuming each carrot.

To implement the delay versus no delay conditions, all participants twice performed their assigned gestures and ate two carrots. The procedure diverged for no-delay and delay condition participants after the third gesture. Participants in the no-delay condition performed the gesture and reported their anticipated enjoyment of the third carrot. Two items - "how much do you anticipate enjoying the next carrot"; "how much do you want to have another carrot" ( $1=$ not at all; 7=very much $)$ - were averaged to form an index of anticipated enjoyment $(\alpha=.89)$. Next, they tasted a carrot from the third bag and reported their enjoyment: "I really enjoyed the carrot"; "I

\footnotetext{
${ }^{1}$ A taste-rating pretest $(n=36)$ confirmed that participants perceive carrots as neutrally-hedonic. For more information, please contact the authors.
} 
savored every bite" (1=not at all; 7=very much) and "How did the carrot taste?" (1=worst;

$7=$ best carrot ever had $)$. These items were averaged to form an enjoyment index $(\alpha=.90)$.

Delay condition participants performed the third set of gestures, and then were told that they would not eat the third carrot immediately but instead would complete an unrelated study. They then rated their anticipated enjoyment, answered questionnaires, and finally ate the third carrot and rated their enjoyment.

\section{Results and Discussion}

Pretest. Fifty-three students (24 female) participated in ritual or random conditions following no-delay condition procedures (although drinking water instead of lemonade). After the third gesture and sip, participants answered: "How much did your hand movements feel like a ritual?" and "How much did you feel like you were doing random actions?" (1=not at all; $7=$ very much). Confirming the manipulation's effectiveness, participants in the ritual condition reported that their movements felt more like a ritual $(M=3.96, S D=1.96)$ and less like random action $(M=4.69, S D=1.99)$ than participants in the random condition $(M=2.41, S D=2.01 ; M=6.30$, $S D=1.24), F s(1,52)>8.10, p s<.01$.

Main experiment: Anticipated enjoyment. We predicted that participants in the ritual condition would both anticipate enjoying and actually enjoy the carrots more than participants in the random conditions. Moreover, we predicted that participants in the ritual delay condition would both anticipate enjoying and actually enjoy the carrots more than participants in the other three conditions.

Consistent with expectations, an ANOVA revealed a significant main effect of ritual

condition on anticipated enjoyment, $F(1,101)=29.57, \mathrm{p}<.001, \eta^{2}=.22$, indicating that participants in the ritual condition reported more anticipated enjoyment $(\mathrm{M}=4.71, \mathrm{SD}=1.45)$ than participants 
in the random condition $(\mathrm{M}=3.33, \mathrm{SD}=1.13)$. There was also a significant main effect of delay, $F(1,101)=4.32, \mathrm{p}<.05, \eta^{2}=.04$, suggesting that participants in the delay condition reported greater anticipated enjoyment $(\mathrm{M}=4.32, \mathrm{SD}=1.55)$ than participants in the no-delay condition $(M=3.77$, $S D=1.36)$. The interaction of ritual and delay did not reach significance, $F(1,101)=1.46, \mathrm{p}=.23$.

We used a planned comparison strategy to test the hypothesized comparisons (Keppel \& Wickens, 2004; Kirk, 1995). Three pairwise comparisons showed that, consistent with predictions, participants in the ritual delay condition $(\mathrm{M}=5.10, \mathrm{SD}=1.32)$ reported higher anticipated enjoyment than did the other three conditions: ritual no-delay $(\mathrm{M}=4.28, \mathrm{SD}=1.49)$, $\mathrm{t}(101)=2.40, \mathrm{p}<.05, \mathrm{~d}=.48$, random delay $(\mathrm{M}=3.44, \mathrm{SD}=1.28), \mathrm{t}(101)=4.74, \mathrm{p}<.001, \mathrm{~d}=.94$, and random no-delay $(\mathrm{M}=3.22, \mathrm{SD}=1.00), \mathrm{t}(101)=5.90, \mathrm{p}<.001, \mathrm{~d}=1.18$ (Figure 1).

Analyses within the delay and no-delay conditions also revealed the positive effects of ritualized compared to random gestures on anticipated enjoyment. Participants in the ritual condition reported great anticipated enjoyment both when there was a delay, $\mathrm{t}(101)=4.74, \mathrm{p}<.001$, $\mathrm{d}=.94$, and when there was no delay, $\mathrm{t}(101)=2.94, \mathrm{p}<.01, \mathrm{~d}=.59$. These results suggest that rituals heighten anticipation regardless of delay condition — and that a delay enhances their effects even more.

Main experiment: Experienced enjoyment. A 2 (ritual vs. random) by 2 (delay vs. nodelay) ANOVA revealed a significant main effect for ritual condition, $F(1,101)=18.87, \mathrm{p}<.001$, $\eta^{2}=.16$, indicating that participants in the ritual condition reported higher enjoyment $(M=4.80$, $\mathrm{SD}=1.49)$ than participants in the random condition $(\mathrm{M}=3.69, \mathrm{SD}=1.08)$. Similar to anticipated enjoyment, a significant main effect of delay was also found, $F(1,101)=6.17, p<.05, \eta^{2}=.06$, suggesting that participants in the delay condition reported higher experienced enjoyment 
$(\mathrm{M}=4.58, \mathrm{SD}=1.63)$ than participants in the no-delay condition $(\mathrm{M}=3.93, \mathrm{SD}=1.08)$. The interaction between delay and ritual was not significant, $\mathrm{F}<1$.

Planned comparisons tested our predictions. Participants in the ritual delay condition $(\mathrm{M}=5.20, \mathrm{SD}=1.69)$ reported significant higher experienced enjoyment than participants in the ritual no-delay condition $(\mathrm{M}=4.35, \mathrm{SD}=1.15), \mathrm{t}(101)=2.48, \mathrm{p}<.05, \mathrm{~d}=.49$, random delay condition $(\mathrm{M}=3.88, \mathrm{SD}=1.29), \mathrm{t}(101)=3.76, \mathrm{p}<.001, \mathrm{~d}=.75$, and random no-delay condition $(\mathrm{M}=3.49$, $\mathrm{SD}=.82), \mathrm{t}(101)=4.96, \mathrm{p}<.001, \mathrm{~d}=.99$ (Figure 2$)$.

Participants in the ritual condition reported higher experienced enjoyment both with and without a delay: delay: $\mathrm{t}(101)=3.76, \mathrm{p}<.001$; no-delay: $\mathrm{t}(101)=2.39, \mathrm{p}<.05, \mathrm{~d}=.48$. In parallel to the results on anticipated enjoyment, these results confirm that rituals benefit enjoyment whether there is or is not a delay between the ritual and the opportunity to consume — and that a delay amplifies enjoyment even more.

Discussion. Experiment 2 demonstrated that rituals heighten both anticipated and experienced enjoyment. The no-delay conditions demonstrate that participants who first performed systematic, repetitive movements enjoyed consuming more than participants who performed non-systematic, random movements. Moreover, separating the ritual performance from immediate consumption heightened appreciation ever further: participants who performed a ritual but were required to wait before consuming reported greater anticipated and experienced enjoyment relative to other conditions. Last, we note that these results were obtained with carrots, which are not universally held in high regard in terms of taste.

\section{Experiment 3: Does Personal Involvement Matter?}

The primary goal of Experiment 3 was to manipulate involvement to offer support for our contention that personal involvement is a key driver of the enhancing effects of rituals. We tested 
whether merely seeing a ritual performed is enough to enhance consumption, or whether the effects of rituals will emerge more when performing the ritual oneself. On the one hand, observing behavior can trigger processes similar to performing behavior oneself (Ackerman et al., 2009), suggesting that there is no difference between observing and enacting rituals on consumption. On the other hand, our proposed mediator, intrinsic involvement, seems more likely when one performs behavior than merely watches it (Walsh \& Rosenbaum, 2009). Therefore, we predicted that merely observing rituals would not be as influential on consumption outcomes (here, flavorful) as performing rituals.

Experiment 2 also made several methodological changes. We switched from using chocolate to lemonade and used a different ritual from Experiment 1. Testing our hypotheses with different consumption experiences and ritualistic behavior builds confidence that our results are not due to specific circumstances. We also tested whether rituals impact emotions in order to rule out mood as an explanation.

\section{Method}

Participants and design. Forty students ( 23 female, $\left.\mathrm{M}_{\mathrm{age}}=20.50, \mathrm{SD}=2.15\right)$ participated in exchange for extra course credit. Students were randomly assigned to one of the two conditions: self-ritual versus other-ritual.

Procedure. In a study on product tasting, self-ritual condition participants were given steps to make a glass of lemonade. They poured half of a packet of lemonade powder and enough water for half of the glass, then stirred the mixture and waited 30 seconds. Next, they poured the remainder of the powder and enough water to top up the glass, stirred, and waited 30 seconds. In the other-ritual condition, participants observed the experimenter perform these same steps. All participants then tasted the lemonade. 
As in Experiment 1, participants rated the flavorful of the lemonade using three items (sweet/sugary/balanced, $\alpha=.73$ ). Last, participants completed the Positive and Negative Affect Schedule (PANAS, Watson, Clark, \& Tellegen, 1988; 1=very slightly; 5=extremely) to assess positive $(\alpha=.87)$ and negative affect $(\alpha=.77)$.

\section{Results and Discussion}

Consistent with predictions, participants who performed the ritual reported that the lemonade tasted more flavorful $(\mathrm{M}=4.55, \mathrm{SD}=1.00)$ than did participants who watched the experimenter perform the ritual $(\mathrm{M}=3.75, \mathrm{SD}=1.44) \mathrm{t}(38)=2.04, \mathrm{p}<.05, \mathrm{~d}=.65$. Importantly, we found no difference in positive or negative affect as a function of condition, ts $<1.40$, ns.

Discussion. Rituals seem to increase the flavor of the consumption experience more when performed by the consumer rather than someone else. Hence, merely observing a ritual was less effective in enhancing consumption than performing those rituals oneself - which suggests that the best way to enjoy a glass of wine may be to perform the ceremonial bottle opening oneself rather than foist it off to a fellow party-goer. The beneficial effects of rituals also do not appear to be linked to changes in positive or negative mood.

\section{Experiment 4: Explaining the Beneficial Effects of Rituals for Consumption}

While Experiment 3 demonstrated a moderating role for personal involvement, in Experiment 4 we assessed involvement directly in order to demonstrate its mediating role in explaining the beneficial effects of rituals on consumption. We operationalized involvement as intrinsic interest using a subscale of a well-validated questionnaire assessing the components of flow experiences (Trevino \& Webster, 1992). We predicted that compared to a non-ritual condition, rituals would lead to higher levels of intrinsic involvement, which would play a mediating role in enhancing consumption. Further, we predicted that the process would be 
specific to keener intrinsic interest and not to other possible mediators, and therefore tested specificity by including other dimensions of flow.

\section{Method}

Participants and design. Eighty-seven adults (33 female; 65 students; $M_{\text {age }}=22.51, S D$ $=2.61$ ) participated in exchange for $\$ 15$. They were recruited through a university subject pool. Participants were randomly assigned to one of the two conditions: ritual versus no ritual.

Procedure. The procedure was similar to Experiment 1. In addition to enjoyment $(\alpha=.85)$ and willingness-to-pay were three-item indices measuring control $(\alpha=.72)$, attention focus $(\alpha=.77)$, curiosity $(\alpha=.95)$, and intrinsic interest ( $\alpha=.69$; Trevino $\&$ Webster, 1992). Items on the latter were: "Eating the chocolate bored / was fun / was intrinsically interesting" (1=not at all; $7=$ very $\mathrm{much})$.

\section{Results and Discussion}

Consumption experience. Participants in the ritual condition were willing to pay more for the chocolate $(\mathrm{M}=\$ 0.45, \mathrm{SD}=0.33)$ than participants in the no-ritual condition $(\mathrm{M}=\$ 0.30$, $\mathrm{SD}=0.25), \mathrm{t}(85)=2.42, \mathrm{p}<.02, \mathrm{~d}=.52$. Rituals also enhanced chocolate's pleasure. Compared to participants in the no-ritual condition, those in the ritual condition reported greater enjoyment of the consumption experience $(\mathrm{M}=6.12, \mathrm{SD}=0.85$ v s. $\mathrm{M}=5.50, \mathrm{SD}=1.16 ; \mathrm{t}(85)=2.81, \mathrm{p}<.01$, $\mathrm{d}=.62)$.

Intrinsic interest. As predicted, performing rituals influenced intrinsic interest in the ensuing chocolate tasting, $\mathrm{t}(85)=2.53, \mathrm{p}<.02, \mathrm{~d}=.54$. Participants in the ritual condition reported greater intrinsic interest than those in the no-ritual condition $(\mathrm{M}=4.99, \mathrm{SD}=1.11 \mathrm{vs.} \mathrm{M}=4.37$, $\mathrm{SD}=1.18)$. 
Other subscales of flow. The positive effect of rituals was specific to increasing intrinsic interest. Participants in the ritual condition reported similar levels of control, attention focus, and curiosity as those in the no-ritual condition ( $\mathrm{ps}>.20)$.

Mediation. We tested whether intrinsic interest mediated the relationship between rituals and enjoyment of the consumption experience. When controlling for condition, intrinsic interest predicted enjoyment $(\beta=.43, \mathrm{p}<.001)$. After controlling for intrinsic interest, the effect of condition on enjoyment decreased from $\beta=.29, \mathrm{p}=.006$ to $\beta=.18, \mathrm{p}=.073$, (95\% bias-corrected CI $=[0.06,0.54])$, thereby indicating full mediation.

A similar analysis using WTP as the dependent measure also supported intrinsic interest as the key process. When controlling for condition, intrinsic interest predicted WTP ( $\beta=.27$, $\mathrm{p}<.02$ ). After controlling for intrinsic interest, the conditional effect on WTP decreased from $\beta=.25, p=.018$ to $\beta=.18, p=.09$ (95\% bias-corrected $\mathrm{CI}=[0.01,0.10])$, again indicating full mediation.

Discussion. Experiment 4 replicated our previous findings on the beneficial effects of rituals on the pleasure of consuming. Importantly, mediation analyses demonstrated that intrinsic interest drove the relationship between performing rituals and how much people enjoyed consuming and the value they placed on the product they just consumed.

\section{General Discussion}

Rituals often make life better. Obsessives find activities less stressful when they are permitted to perform their chosen rituals (e.g., Rachman \& Hodgson, 1980) and space feels safer and food purer in the presence of rituals (Dulaney \& Fiske, 1994). We explored the impact of rituals in making a ubiquitous aspect of everyday life more enjoyable - consumption. Four experiments supported our hypothesis that rituals enhance consumption. 
Our results were robust to methodological and sample differences. We studied college students and community adults, as well as diverse ritualized behaviors — from stirring and pouring liquid to breaking and unwrapping food to rapping knuckles on a table. When these behaviors followed a systematic, ritualistic pattern, then enjoyment increased; when they did not or when the behaviors performed were more random and therefore less ritualistic, enjoyment was less. We found that rituals enhanced consumption of sweet (chocolate), tart (lemonade), and healthy (carrots) items. We assessed subjective ratings (flavor, enjoyment), value (willingness to pay), and actual behavior (duration spent savoring). Across metrics, rituals improved the consumption experience.

We not only documented whether rituals enhance consumption - they do - but also the process by which that enhancement occurs. Rituals seem to improve the consumption experience because they lead to greater involvement and interest. Following recommendation of Spencer, Zanna, and Fong (2005), we used an approach that supports a role for involvement via both moderation and mediation. Experiment 3 showed that merely observing a ritual being performed does not enhance consumption as much as personal involvement in performing that ritual, while Experiment 4 demonstrated that when people perform a ritual, their intrinsic interest increases; this increased involvement in turn leads to more enjoyable consumption. In sum, performing rituals heightens the involvement that people feel while consuming, and feeling deeply involved potentiates the experience.

Four avenues for future direction seem worthy of discussion. First, future studies could examine what kinds of consumption experiences are most likely to improve with rituals. Experiments 1 and 3 showed that rituals augment flavor, which is among the most important determinants of which foods people choose to eat (Glanz, Kristal, Tilley, \& Hirst, 1998). We do 
not claim that rituals will aid all forms of consumption, however, because boosting the flavor of some tastes may be offputting. Research on the effect of rituals to alter the taste of truly unenjoyable foods would be welcome.

Second, there might be cognitive effects or lay beliefs about rituals that pertain to the ritual-consumption effect documented here. It could be that rituals act akin to a mindfulness induction, which might be part of the causal process. Moreover, that participants in Experiment 2's pretest could intuit that their repeated performances constituted a ritual suggests that some ritual effects could come about because of lay beliefs.

Third, our results were marked by fairly big effect sizes. This likely came about for several reasons. One is that ritualized behavior likely encompasses several mechanisms. In addition to involvement, rituals might serve a preparatory, symbolic, or palliative function. Other work has shown that rituals restore control after loss (Norton \& Gino, in press). Two is that our participants performed actual behavior, which itself could have triggered several mechanisms (see Baumeister, Vohs, \& Funder, 2007). Work into which settings and outcomes tap into which mechanisms will reveal more about the compellingness of ritualized behavior.

Fourth, the social dimension of rituals deserves further attention. Many common consumption rituals - such as the birthday cake example mentioned earlier - are inherently social in nature. Although our results demonstrate that rituals can enhance consumption even in the absence of social factors, enacting rituals in a rich social context may have additional benefits benefits that may extend beyond enhancing consumption. For instance, families that consistently enact ritual behaviors have children with better self-control and academic performance than families that do not make use of rituals (Brody \& Flor, 1997; Fiese, 2002; Seaton \& Taylor, 
2003). This suggests that perhaps enacting rituals around food as a family would not only heighten the consumption experience but lead to more broadly positive outcomes.

\section{Conclusion}

Rituals have a surprising degree of influence over how people experience what comes next. We examined the everyday experiences of eating and drinking in order to systematically test the effects of rituals on consumption, and consistently observed that consumption was more pleasurable than it would be otherwise. Because our results suggest that rituals can enhance the pleasure derived from even neutral stimuli (here, carrots), our results suggest that rituals could be put to use to make a wide variety of desirable behaviors - from eating healthily to exercising to practicing safe sex - more pleasurable. Rituals, then, might serve as a covert means to get people to do a little more of what makes life worth living. 


\section{References}

Ackerman, J.A., Goldstein, N.J., Shapiro, J.R., \& Bargh, J.A. (2009). You wear me out: The vicarious depletion of self-control. Psychological Science, 20, 326-332.

Baumeister, R. F., Vohs, K. D., \& Funder, D. C. (2007). Psychology as the science of selfreports and finger movements: Whatever happened to actual behavior? Perspectives on Psychological Science, 2, 396 - 403.

Brody, G.H., \& Flor, D.L. (1997). Maternal psychological functioning, family process, and child adjustment in rural, single-parent African American families. Developmental Psychology, 33, 1000-1011.

Cohn, P. J. (1990). Pre-performance routines in sport: Theoretical support and practical applications. Sport Psychologist, 4, 301-312.

Crews, D. J. \& Boutcher, S.H. (1986). An exploratory observational behavior analysis of professional golfers during competition. Journal of Sport Behavior, 9, 51-58.

Dulaney, S., \& Fiske, A.P. (1994). Cultural rituals and obsessive-compulsive disorder: Is there a common psychological mechanism? Ethos, 22, 243-283.

Fiese, B.H. (2002). Routines of daily living and rituals in family life: A glimpse of stability and change during the early child-raising years. Zero to Three, 22(4), 10-13.

Förster, J., Liberman, N., \& Friedman, R.S. (2007). Seven principles of goal activation: A systematic approach to distinguishing goal priming from priming of non-goal constructs. Personality and Social Psychology Review, 11, 211-233.

Glanz, K., Kristal, A.R., Tilley, B.C., \& Hirst, K. (1998). Psychosocial correlates of healthful diets among male auto workers. Cancer Epidemiology, Biomarkers and Prevention, 7, $119-126$. 
Keppel, G., \& Wickens, T.D. (2004). Design and analysis. A researcher's handbook (4 ${ }^{\text {th }}$ ed.). Upper Saddle River, NJ: Pearson Prentice Hall.

Kirk, R.E. (1995). Experimental design: Procedure for behavioral sciences ( $3^{\text {rd }}$ ed). Belmont, CA: Brooks/Cole.

Le Billion, K. (2012). French kids eat everything: How our family moved to France, cured picky eating, banned snacking, and discovered 10 simple rules for raising happy, healthy eaters. New York: William Morrow.

Loewenstein, G. (1987). Anticipation and the valuation of delayed consumption. Economic Journal, 97, 666-684.

Norton, M.I. \& Gino, F. (in press). Rituals alleviate grieving for loved ones, lovers, and lotteries. Journal of Experimental Psychology: General.

Quoidbach, J, Dunn, E.W., Petrides, K.V., \& Mikolajczak, M. (2010). Money giveth, money taketh away: The dual effect of wealth on happiness. Psychological Science, 21, 759-763.

Rachman, S.J. \& Hodgson, R. (1980). Obsessions and compulsions. Englewood Cliffs, NJ: Prentice Hall.

Rook, D.W. (1985). The ritual dimension of consumer behavior. Journal of Consumer Research, $12,251-264$.

Rossano, M.J. (2012). The essential role of ritual in the transmission and reinforcement of social norms. Psychological Bulletin, 138, 529-549.

Seaton, E.K. \& Taylor, R.D. (2003). Exploring familial processes in urban, low-income AfricanAmerican families. Journal of Family Issues, 24, 627-644.

Schippers, M., \& Van Lange, P. A. M. (2006). Superstition as a psychological placebo in top sport. Journal of Applied Social Psychology, 36, 2532-2553. 
Spencer, S.J., Zanna, M.P., \& Fong, G. T. (2005). Establishing a causal chain: Why experiments are often more effective than meditational analyses in examining psychological processes. Journal of Personality and Social Psychology, 89, 845-851.

Tannahill, R. (1995). Food in history. New York: Three Rivers Press.

Trevino, L. K., \& Webster, J. (1992). Flow in computer-mediated communication. Communication Research, 19:5, 539-573.

van der Hart, O. (1983). Rituals in psychotherapy. New York: Irvington.

Visser, M. (1992). The rituals of dinner: The origins, evolution, eccentricities, and meaning of table manners. New York, Penguin Books.

Walsh, M.M. \& Rosenbaum, D.A. (2009). Deciding how to act is not achieved by watching mental movies. Journal of Experimental Psychology: Human Perception and Performance, 35, 1481-1489.

Watson, D., Clark, L.A., \& Tellegen, A. (1988). Development and validation of brief measures of Positive and Negative Affect: The PANAS scales. Journal of Personality and Social Psychology, 54, 1063-1070. 


\section{Figures}

Figure 1. Anticipated enjoyment, Experiment 2. Error bars represent standard errors.

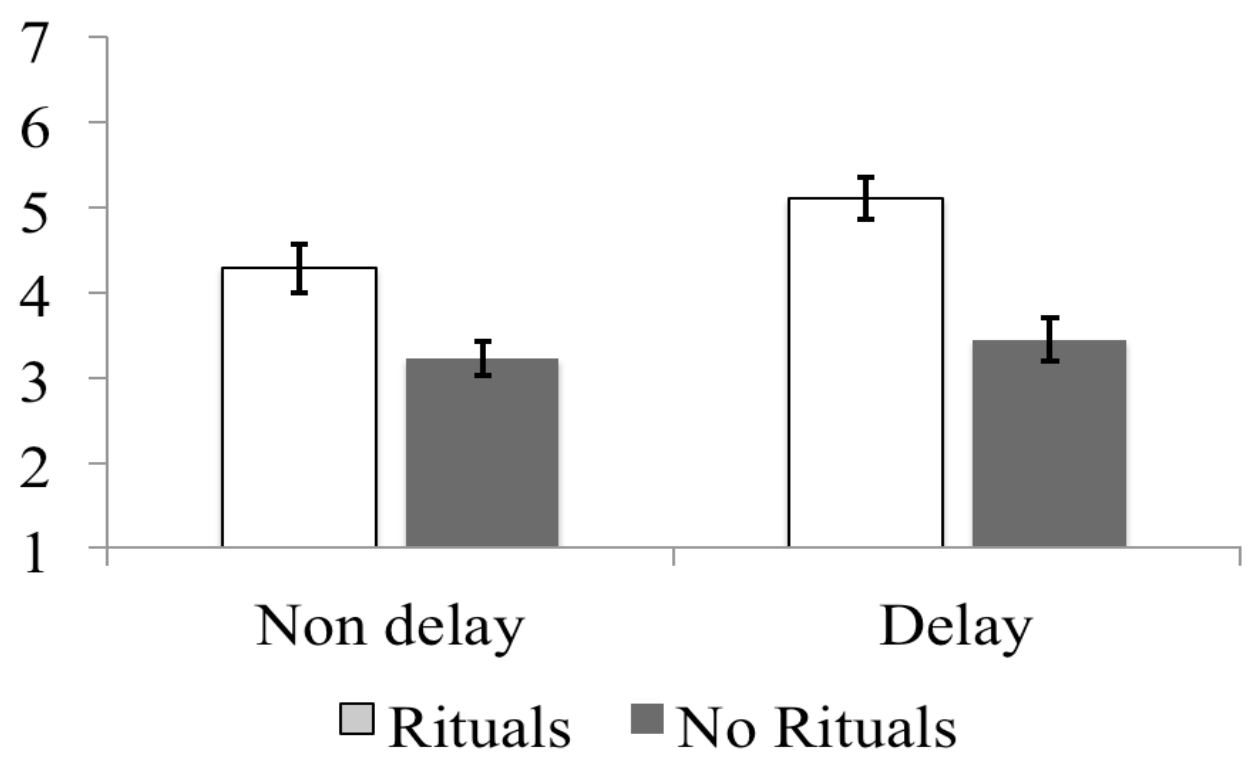


Figure 2. Experienced enjoyment, Experiment 2. Error bars represent standard errors

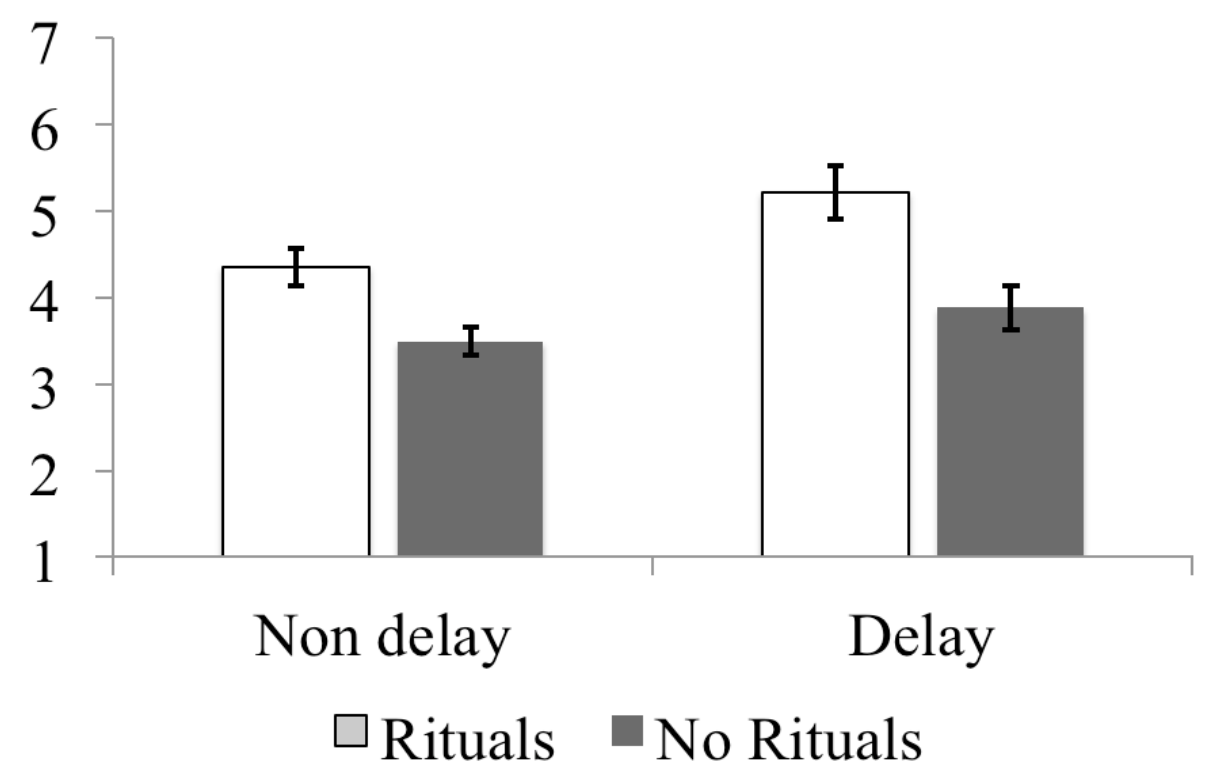

